\title{
Type and frequency of cardiac defects in embryofetal alcohol syndrome Report of 16 cases
}

\author{
HERMANN LÖSER ${ }^{1}$ AND FRANK MAJEWSKI \\ From the Department of Paediatric Cardiology at the Children's Hospital, University of Tübingen, \\ Federal Republic of Germany
}

Within a period of 3 years, 56 infants and children with embryofetal alcohol syndrome have been detected and examined for heart defects. All children were from mothers who had been addicted to alcohol even during pregnancy and they showed a typical pattern of malformations, as described by Lemoine et al. (1968) and fones et al. (1973).

In 16 cases cardiovascular malformations were confirmed by heart catheterisation or pathological examination. The overall incidence of heart defects in this syndrome was 29 per cent. The incidence rises to nearly 50 per cent in the more severe types of this syndrome. Atrial septal defects were found to be the most common heart defect (10 out of 16 cases); ventricular septal defects and other variable malformations occurred less frequently.

The high incidence of heart defects indicates that alcoholism during pregnancy has to be considered as a serious and preventable cause of congenital heart disease.

Previous clinical studies on the embryofetal alcohol syndrome resulting from severe maternal alcoholism in pregnancy indicate that alcohol is a teratogenic agent. Alcoholism during pregnancy may produce multiple malformations including heart defects in the offspring. We owe it to Lemoine et al. (1968) in Nantes, France, and Jones et al. (1973, 1974) in the USA for recognising a typical pattern of malformations in this syndrome, which is characterised by the following basic features: prenatal and postnatal growth retardation; retardation of mental, psychomotor, and motor development; craniofacial dysplasia, particularly microcephaly, short palpebral fissures, ptosis of the upper lids, epicanthic folds, upturned nostrils ('nez court en trompettes'), and mandibular hypoplasia (Fig. 1A and B). Other malformations are frequently found, such as heart defects, abnormalities of the limbs or genitals, dermatoglyphs, etc. The malformations vary in individuals in number and in severity.

The prevalence and types of cardiac defects in the embryofetal alcohol syndrome are still matters of controversy. On the basis of our first reports of 8 confirmed cases, atrial septal defect was thought to

'Present address: Abteilung fur Pädiatrische Kardiologie der Universitätskinderklinik, 4400 Münster, Robert-Koch-Strasse 31, Germany.

Received for publication 11 November 1976 be the most frequent abnormality (Löser et al., 1975, 1976). On the basis of other reports, however, the most frequent defect seemed to be ventricular septal defect. Little information is available concerning the frequency of cardiovascular malformations in this syndrome. Since an increase in the number of alcohol-consuming women of childbearing age is to be expected in all industrial countries, the question of cardiovascular malformations in the embryofetal alcohol syndrome is important both prophylactically and therapeutically.

\section{Subjects and methods}

Following our first reports of heart diseases in embryofetal alcohol syndrome (Löser et al., 1975), we were able to detect in our clinic a total of 16 infants and children with congenital heart disease in 56 cases with the syndrome (Bierich et al., 1976; Majewski et al., 1976). The observation spanned a 3 -year period. In all these 56 cases the heart was examined clinically and chest radiographs and electrocardiograms were obtained. If reasonably certain indications of cardiac defect were present, heart catheterisation and angiocardiography were performed.

All patients were children of mothers who had 


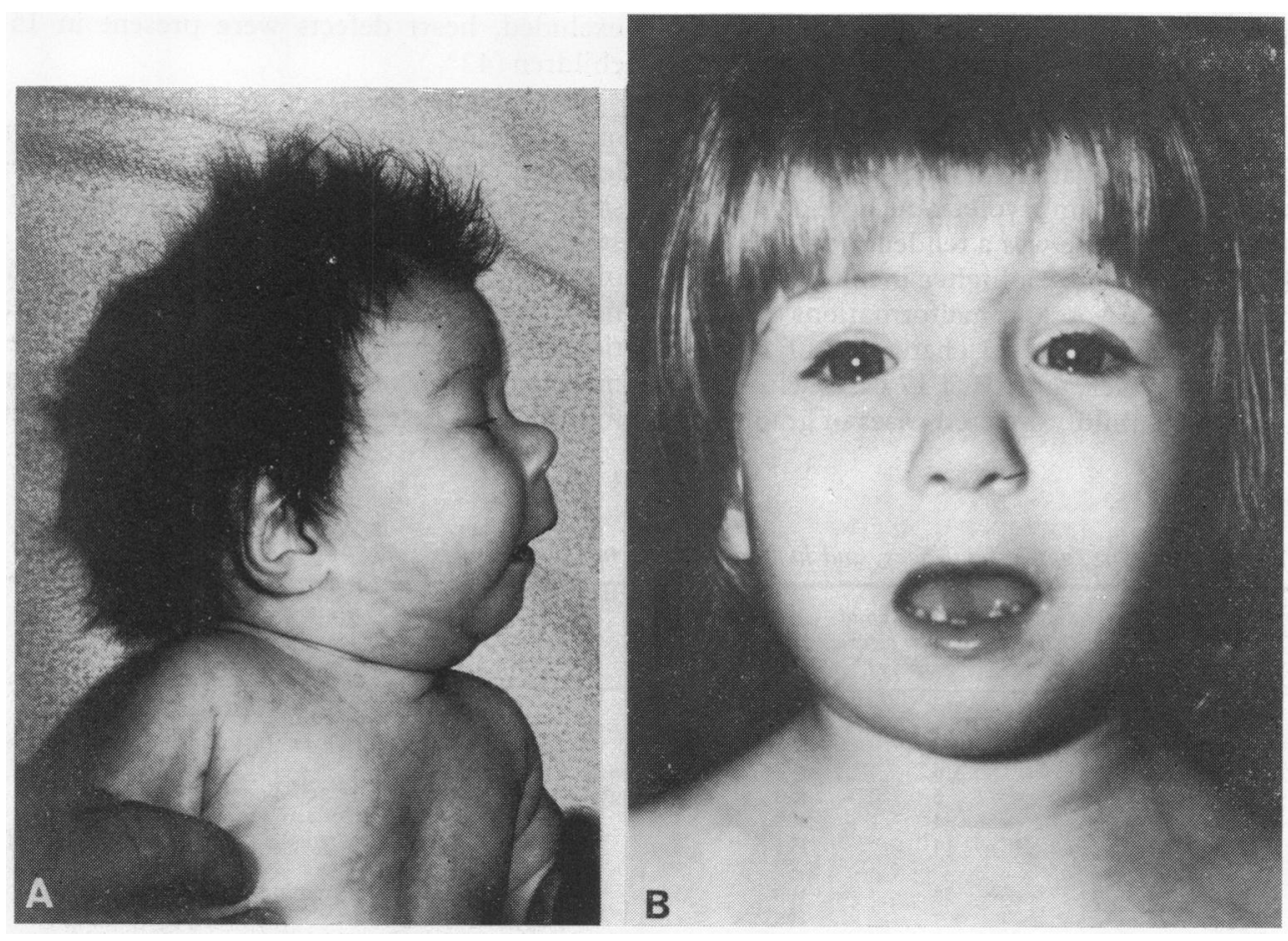

Fig. 1 (A) and (B) Typical facies of children with embryofetal alcohol syndrome. The narrow palpebral fissures, the upturned nostrils, the hypoplasia of the mandible, and the vermilion border of the upper lip are noteworthy.

drunk excessive amounts of alcohol for several years, even during pregnancy. An estimate of the alcohol intake was obtained from case histories and expressed as grams of ethanol per day. In addition, data concerning alcohol-related diseases, duration of pregnancy, birthweights, and gestational ages were collected. Children of mothers who were only occasional drinkers were not included. The minimal alcohol consumption admitted by the mothers ranged from 75 to $350 \mathrm{~g} /$ day. As is typical with alcoholics, the actual amounts must be assumed to be higher and, therefore, could not be established precisely. Additional drug intake was noted in as far as it was admitted.

Because of the broad spectrum of symptoms in this syndrome, the 56 cases of embryofetal alcohol syndrome have been divided into three groups according to the occurrence and severity of mental, neurological, and physical abnormalities (Majewski et al., 1976).

Grade 1 (20 cases): oligosymptomatic cases with only slight expression of morphological features. Except for reduced body weight and microcephaly these children showed no manifestations typical of the syndrome. Abnormal development in utero was in some cases less important than postnatal growth retardation which usually persisted into later childhood. Motor development was moderately delayed in most cases. Mental age did not seem to differ from that of normal subjects.

Grade 2 (19 cases): moderately affected cases. The craniofacial dysmorphism was not striking, but sufficiently pronounced to be apparent to those with some experience in its recognition. In this group there were no neurological manifestations, except for hyperexcitability and hypotonia of the muscles. Mental and physical development were moderately delayed.

Grade 3 (17 cases): severely affected cases with all or nearly all the typical abnormalities. All cases showed pronounced craniofacial changes: microcephaly, epicanthic folds, ptosis, upturned nostrils, thin vermilion border of the upper lip, and mandibular hypoplasia. Physical, motor, and mental development were seriously delayed in all cases.

\section{Results}

The historical data and catheterisation results in our 16 cases are summarised in Tables 1 and 2. They 
comprise 7 girls and 9 boys between the ages of 1 month and 6 years. Except for cases 13 and 14 the birthweights were below $2500 \mathrm{~g}$, and the data in Table 1 show that these children were premature and/or small for dates at birth. The overall incidence of heart defects in embryofetal alcohol syndrome was 29 per cent. There was a tendency for the more severely affected to have a higher incidence of heart defects: thus cardiovascular malformations occurred in 1 of 20 cases with grade 1 changes, 5 of 19 cases with grade 2 changes, and 10 of 17 cases with grade 3 changes. If the mildly affected cases of grade 1 are excluded, heart defects were present in 15 of 36 children ( $42 \%)$.

Atrial septal defects were found in 10 cases. In one of these distinct displacement of the heart to the left and hypoplastic left pulmonary arteries were shown. In one case of atrial septal defect, catheterisation was not justified during life because of respiratory problems and internal hydrocephalus. The heart is shown in Fig. 2. At histological examination of both ventricles no abnormal structure of the muscle fibres or other signs of cardiomyopathy were found. In all cases additional left-sided defects were

Table 1 Birthweights, gestational ages, and history of maternal alcohol abuse

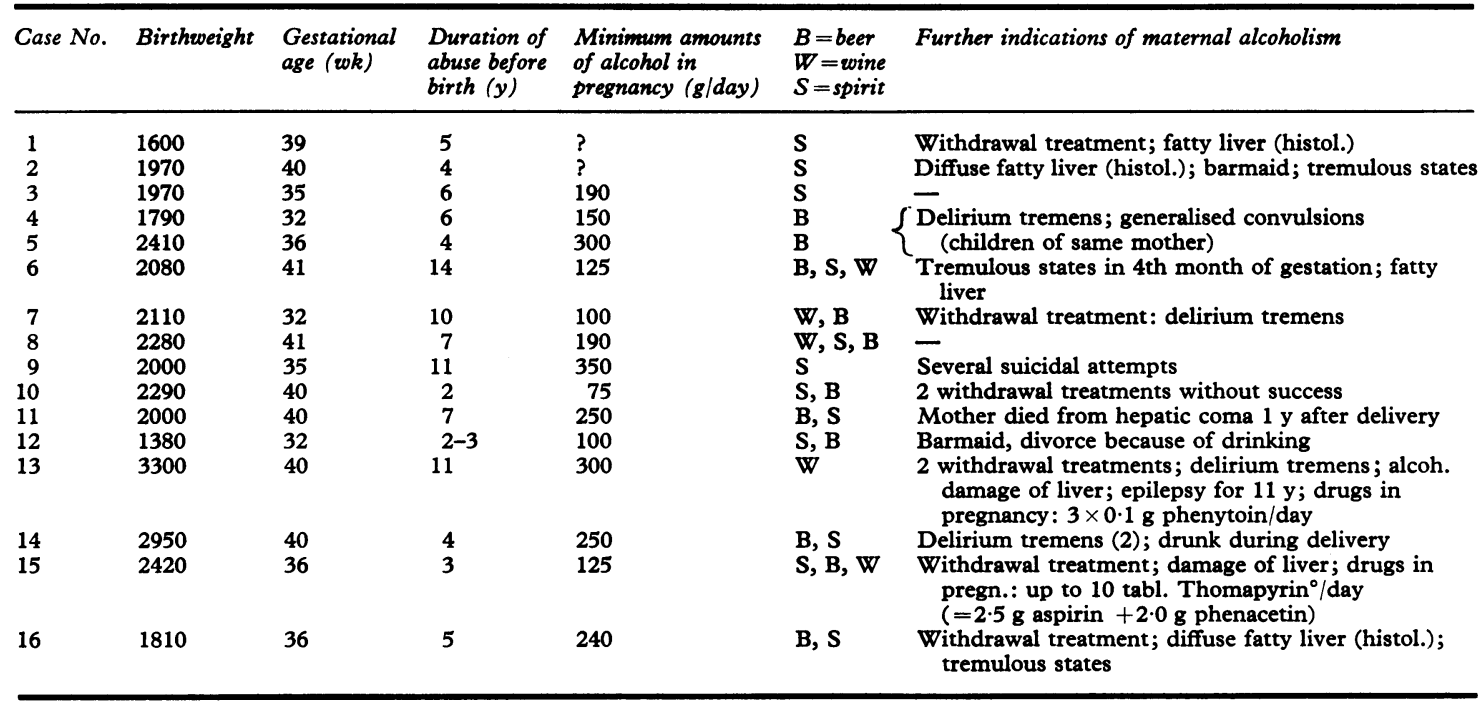

Table 2 Embryofetal alcohol syndrome: results of catheterisation

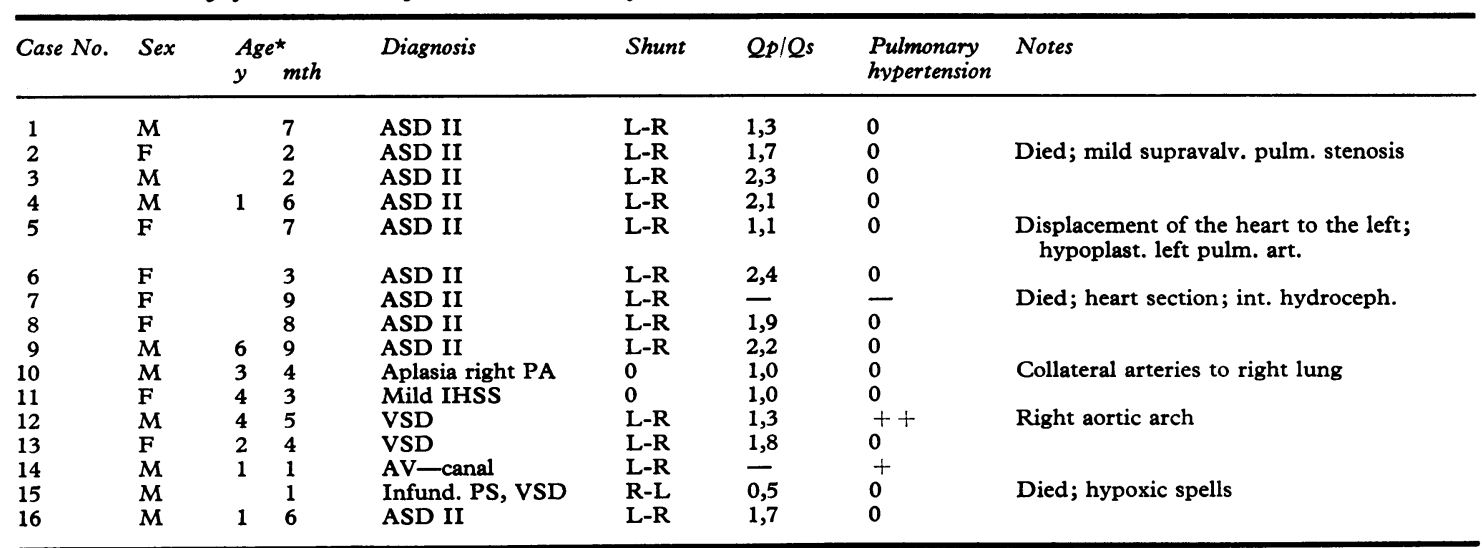

*At time of catheterisation; $+=$ mild, $++=$ moderate; $Q p / Q s=$ pulmonary to systemic flow ratio; PS=pulmonary stencsis. 
excluded by angiocardiography. Electrocardiograms showed no evidence of left axis deviation.

An isolated ventricular septal defect was found in 2 cases, one of which had a right-sided aortic arch and pulmonary hypertension (Fig. 3).

In other isolated cases, variable defects were found. In one case aplasia of the right pulmonary artery was established (Fig. 4), which was also confirmed by lung perfusion scintigraphy. In one case a mild obstruction of the left ventricular outflow tract was found. One case of atrioventricular canal, and one case of infundibular pulmonary stenosis and ventricular septal defect with pronounced cyanosis were also shown.

Two infants died from extracardiac causes (cases 2 and 7), at the ages of 5 and 9 months. One infant died in the course of hypoxic spells and respiratory troubles at the age of 4 months (case 15).

The catheterisation and electrocardiographic data gave no reliable signs of cardiomyopathy in any subject.

\section{Discussion}

The frequent appearance of cardiac defects in the embryofetal alcohol syndrome can now be regarded

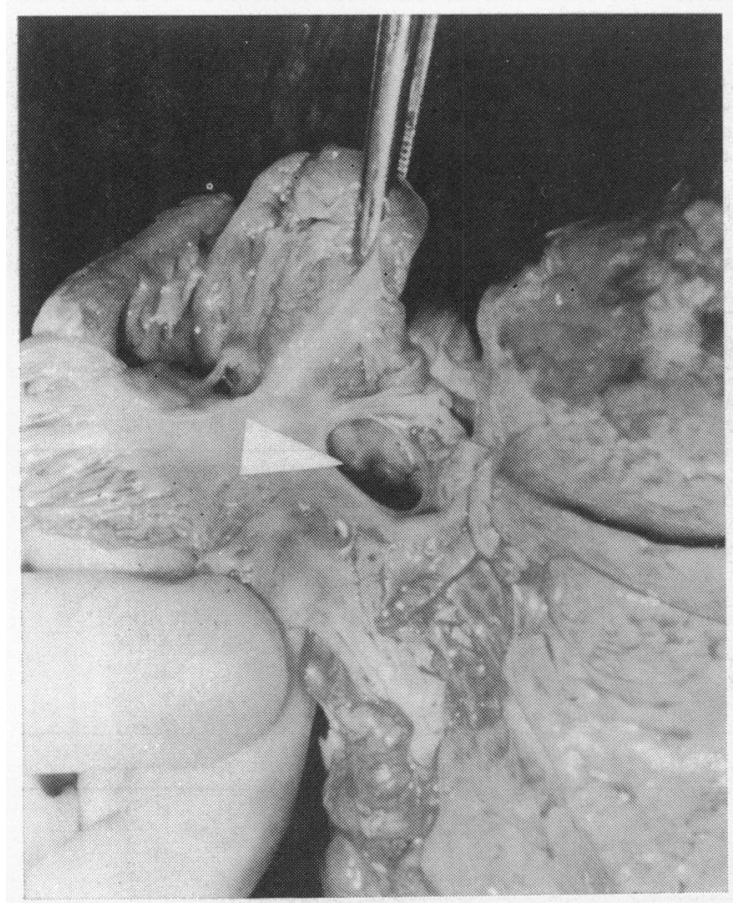

Fig. 2 Case 7. Portion of the heart. The arrow indicates a large atrial septal defect (secundum type). as established. No exact data regarding the frequency of cardiac defects in children from alcoholic mothers are available. There are several reasons for this:

(1) The degree of severity and the expression of

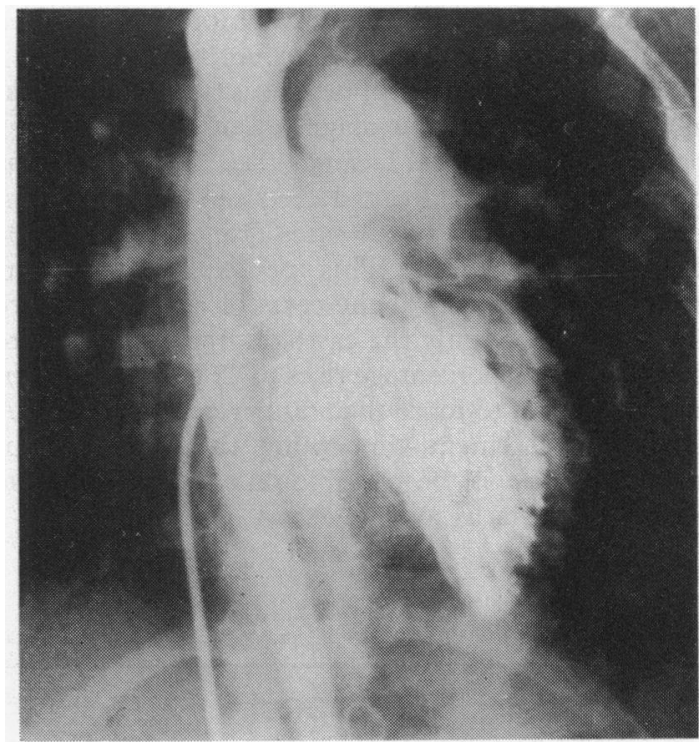

Fig. 3 Case 12. Angiocardiogram after injection into the left ventricle. Filling of the right ventricle and the pulmonary artery. Right-sided aortic arch.

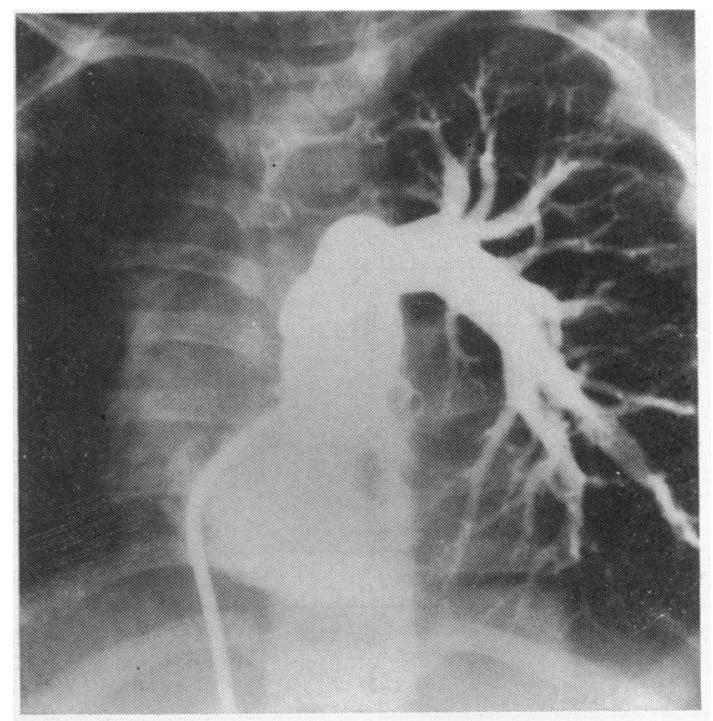

Fig. 4 Case 10. Angiocardiogram showing absence of the right pulmonary artery. 
manifestations varied in our observations and also in other published studies. They range from mild ('formes frustes') to severe cases (grade 1-3, Majewski et al., 1976). This depends more on the drinking pattern and the individual tolerance than on the absolute quantity of alcohol consumed (Majewski et al., 1976). The question remains whether infants with only a slight expression of symptoms should be included in the embryofetal alcohol syndrome.

(2) In many currently reported cases of embryofetal alcohol syndrome, the diagnosis of heart defect is based only on clinical findings (see Table 3 ). It has been suggested that heart defects can be expected in nearly 50 per cent of all cases (Jones et al., 1973; Löser et al., 1975). This percentage, however, seems to be too high if the cases of mild degree are included. But if only the cases of grades 2 and 3 are considered the percentage rises to 42 per cent, and in severe degrees to more than 50 per cent ( 9 of 16). A definitive statement concerning the frequency of heart defects will be possible only when more extensive material is available and investigated.
The influence of concurrent drug intake did not appear to be significant in our study.

In contrast to the currently available reports, particularly that of Jones et al. (1973), the most frequent malformation of the heart is atrial septal defect and not ventricular septal defect. An atrial septal defect was diagnosed in 10 out of 16 cases, an isolated ventricular septal defect in 2 cases. According to the reported clinical observations (Table 3), ventricular septal defect was often suspected, but the typical sharp harsh murmur was seldom described. Noonan (1976) recently presented a paper on 3 cases with embryofetal alcohol syndrome and heart defects. Two of these had tetralogy of Fallot.

Based on experimental studies, particularly the chick embryo and mouse embryo (Sandor, 1968; Chernoff, 1976), it has been confirmed that ethylalcohol affects embryonic development, produces a high mortality rate, and alters early growth as well as differentiation and morphogenesis in cardiac development. Sandor and Elias (1968) described a lack of circulation in beating embryonic hearts after

Table 3 Summary of published cases of embryofetal alcohol syndrome with cardiac defects

\begin{tabular}{|c|c|c|c|c|c|c|c|}
\hline Author & Case No. & Sex & $\begin{array}{l}A g \\
y\end{array}$ & $e_{m}$ & Heart defect & Heart catheter. & Notes \\
\hline $\begin{array}{l}\text { Jones et al. (1973) } \\
\text { Jones and Smith (1973) }\end{array}$ & $\begin{array}{l}1 \\
2 \\
3 \\
4 \\
8 \\
1 \\
2 \\
3\end{array}$ & $\begin{array}{l}F \\
F \\
F \\
F \\
M \\
M \\
F \\
F\end{array}$ & $\begin{array}{l}1 \\
4 \\
3 \\
2 \\
\mathrm{Ne} \\
\mathrm{Ne}\end{array}$ & $\begin{array}{c}11 \\
3 \\
9 \\
6 \\
\text { wborn } \\
\text { wborn } \\
7\end{array}$ & $\begin{array}{l}\text { VSD suspected } \\
\text { ASD } \\
\text { VSD suspected } \\
\text { PDA suspected } \\
\text { VSD suspected } \\
\text { VSD suspected } \\
\text { VSD } \\
\text { VSD suspected }\end{array}$ & $\begin{array}{l}\phi \\
+ \\
? \\
? \\
\phi \\
\phi \\
\phi \\
\phi\end{array}$ & $\begin{array}{l}\text { Spontan. closure } \\
\text { Heart failure } \\
\text { Spontan. closure suspected } \\
\frac{-}{\text { Spontan. closure suspected }} \\
\frac{\text { Died; pathol. examination }}{-}\end{array}$ \\
\hline Palmer et al. (1974) & $\begin{array}{l}2 \\
3\end{array}$ & $\begin{array}{l}\mathrm{F} \\
\mathrm{F}\end{array}$ & $\begin{array}{l}1 \\
1\end{array}$ & $\begin{array}{l}9 \\
9\end{array}$ & $\begin{array}{l}\text { VSD suspected } \\
?\end{array}$ & $\begin{array}{l}\phi \\
\phi\end{array}$ & $\begin{array}{l}\text { Twins } \\
\text { (systolic murmur) }\end{array}$ \\
\hline Saule (1974) & 1 & F & & wborn & VSD suspected & $\phi$ & - \\
\hline Manzke and Grosse (1975) & $\begin{array}{l}4 \\
7\end{array}$ & $\begin{array}{l}M \\
M\end{array}$ & 6 & 9 & $\begin{array}{l}\text { Defect suspected } \\
\text { Mitr. stenosis }\end{array}$ & $\begin{array}{l}\phi \\
+\end{array}$ & $\overline{\text { Infrahepat. stenosis IVC }}$ \\
\hline Reinhold et al. (1975) & 2 & $\mathrm{~F}$ & & 4 & VSD suspected & $\phi$ & - \\
\hline Löser et al. (1975) & $\begin{array}{r}1 \\
2 \\
3 \\
4 \\
5 \\
10 \\
11 \\
12\end{array}$ & $\begin{array}{l}M \\
\mathrm{~F} \\
\mathrm{M} \\
\mathrm{M} \\
\mathrm{F} \\
\mathrm{M} \\
\mathrm{F} \\
\mathrm{M}\end{array}$ & $\begin{array}{l}1 \\
3 \\
4 \\
4\end{array}$ & $\begin{array}{l}7 \\
2 \\
2 \\
6 \\
7 \\
4 \\
3 \\
5\end{array}$ & $\begin{array}{l}\text { ASD } \\
\text { ASD } \\
\text { ASD } \\
\text { ASD } \\
\text { ASD } \\
\text { Aplasia r. PA } \\
\text { Mild IHSS } \\
\text { VSD, r. ao. arch }\end{array}$ & $\begin{array}{l}+ \\
+ \\
+ \\
+ \\
+ \\
+ \\
+ \\
+\end{array}$ & Died, 5th mth \\
\hline Mulvihill et al. (1976) & 2 & $\mathbf{M}$ & & 1 & PAST suspected & $\phi$ & \\
\hline Noonan (1976) & $\begin{array}{l}1 \\
2 \\
3\end{array}$ & $\begin{array}{l}? \\
? \\
?\end{array}$ & $\begin{array}{r}4 \\
6 \\
17\end{array}$ & & $\begin{array}{l}\mathrm{T} / \mathrm{F} \\
\mathrm{T} / \mathrm{F} \\
\text { VSD, PDA }\end{array}$ & $\begin{array}{l}+ \\
+ \\
+\end{array}$ & \\
\hline
\end{tabular}

Abbreviations : ao., aortic; ASD, atrial septal defect; IHSS, idiopathic hypertrophic subaortic stenosis; IVC, inferior vena cava; PA, pulmonary artery; PAST, pulmonary artery stenosis; PDA, persistent ductus arteriosus; T/F, tetralogy of Fallot; VSD, ventricular septal defect. $\phi$, catheterisation not performed. 
exposure to alcohol. Chernoff (1976) noted a higher rate of heart defects on the eighteenth day of gestation in developing mice during exposure to alcohol. The type of defects in the heart and great vessels were, however, not elaborated.

The cardiovascular malformations produced by thalidomide during pregnancy represent a comparable embryotoxic effect on the developing heart (Khera, 1976). Congenital heart disease was found in approximately 19 per cent of the children affected by thalidomide embropathy (Keck et al., 1971). As with thalidomide embryopathy, the critical period for toxic injury to the developing heart is assumed to be between the fourth and sixth week of gestation. It is expected that the spectrum of cardiovascular defects in embryofetal alcohol syndrome is more extensive than has been known up to now.

Previous investigations indicate that it is the ethanol itself and not its metabolites, such as acetaldehyde, that is responsible for the direct damage to the embryo, since alcohol is able to cross the placental barrier readily. Moreover, it is known that alcohol metabolism is deficient in chronic alcoholics and also in the human fetal liver. The concentration of alcohol dehydrogenase in the human fetal liver is extremely low (Pikkarainen and Räihä, 1967) and ethanol clearance is reduced (Seppälä et al., 1971), which enhances the toxic influence.

It is surprising that widespread alcoholism during pregnancy has not been recognised earlier as a cause of congenital heart disease, since many women as well as men have been addicted to alcohol for generations.

We thank Prof. Dr. med. Jüngst, Univ. - Kinderklinik Mainz, West Germany, for permission to include case 14.

\section{References}

Bierich, J. R., Majewski, F., Michaelis, R., and Tillner, I. (1976). Uber das embryo-fetale Alkohol-Syndrom. European fournal of Pediatrics, 121, 155-177.

Chernoff, G. F. (1976). A mouse model of the fetal alcohol syndrome. Teratology, 11, 14A.

Jones, K. L., and Smith, D. W. (1973). Recognition of the fetal alcohol syndrome in early infancy. Lancet, 2, 999-1001.

Jones, K. L., Smith, D. W., Streissguth, A. P., and Myrianthopoulos, N. C. (1974). Outcome in offspring of chronic alcoholic women. Lancet, 1, 1076-1078.
Jones, K. L., Smith, D. W., Ulleland, C. N., and Streissguth, A. P. (1973). Pattern of malformation in offspring of chronic alcoholic mothers. Lancet, 1, 1267-1271.

Keck, E. W., Roloff, D., and Markworth, P. (1971). Kardiovaskuläre Befunde bei Kindern mit Thalidomid-DysmelieSyndrom. Verhandlungen der Deutschen Gesellschaft für Kreislaufforschung, 37, 364-370.

Khera, K. S. (1976). Fetal cardiovascular and other defects induced by thalidomide in cats. Teratology, 11, 65-72.

Lemoine, P. H., Harousseau, H., Borteyru, J. P., and Menuet, J.-C. (1968). Les enfants de parents alcooliques. Anomalies observées apropos de 127 cas. Ouest-Médical, 25, 477-482.

Löser, H., Majewski, F., Apitz, J., and Bierich, J. R. (1975). Kardiovaskuläre Fehlbildungen bei fetalem Alkoholsyndrom. Zeitschrift für Kardiologie, Suppl. 2, 91.

Löser, H., Majewski, F., Apitz, J., and Bierich, J. R. (1976). Kardiovaskuläre Fehlbildungen bei embryofetalem Alkohol-Syndrom. Klinische Padiatrie, 188, 233-240.

Majewski, F., Bierich, J. R., Löser, H., Michaelis, R., Leiber, B., and Bettecken, F. (1976). Zur Klinik und Pathogenese der Alkohol-Embryopathie. Bericht über 68 Fälle. Münchener medizinische Wochenschrift, 118, 1635-1642.

Manzke, H., and Grosse, F. R. (1975). Inkomplettes und komplettes 'fetales Alkoholsyndrom' bei drei Kindern einer Trinkerin. Medizinische Welt, 26, 709-712.

Mulvihill, J. J., Klimas, J. T., Stokes, D. C., and Risemberg, H. M. (1976). Fetal alcohol syndrome: seven new cases American Fournal of Obstetrics and Gynecology, 125, 937941.

Noonan, J. A. (1976). Congenital heart disease in the fetal alcohol syndrome. American fournal of Cardiology, 37, 160.

Palmer, R. H., Ouellette, E. M., Warner, L., and Leichtman, S. R. (1974). Congenital malformations in offspring of a chronic alcoholic mother. Pediatrics, 53, 490-494.

Pikkarainen, P., and Räihä, N. C. R. (1967). Development of alcohol dehydrogenase activity in the human liver. Pediatric Research, 1, 165-168.

Reinhold, L., Hütteroth, H., and Schulte-Wissermann (1975). Das fetale Alkohol-Syndrom. Fallbericht über 2 Geschwister. Münchener medizinische Wochenschrift, 117, 17311734.

Sandor, S. (1968). The influence of aethyl alcohol on the development of the chick embryo. II. Revue Roumaine Embryologie et de Cytologie. Série d'embryologie, 5, 167-171.

Sandor, S., and Elias, S. (1968). The influence of aethylalcohol on the development of the chick embryo. Revue Roumaine Embryologie et de Cytologie. Série d'embryologie, 5, 51-76.

Saule, H. (1974). Fetales Alkohol-Syndrom. Ein Fallbericht. Klinische Padiatrie, 186, 452-455.

Seppälä, M., Räihä, N. C. R., and Tamminen, V. (1971). Ethanol elimination in a mother and her premature twins. Lancet, 1, 1188-1189.

Requests for reprints to Dr. H. Löser, Abteilung für pädiatrische Kardiologie, Universitätskinderklinik, 4400 Münster, Robert-Koch-S trasse 31, Germany. 